Report No: ACS18400

Islamic Republic of Pakistan

Strengthening Local Providers for Improved Rura Water Supply in Pakistan

\{enter report sub-title here\}

\{enter report date here\}

GWA06

SOUTH ASIA

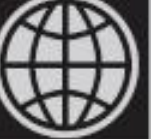


Standard Disclaimer:

This volume is a product of the staff of the International Bank for Reconstruction and Development/ The World Bank. The findin interpretations, and conclusions expressed in this paper do not necessarily reflect the views of the Executive Directors of The World Bank or $t$ governments they represent. The World Bank does not guarantee the accuracy of the data included in this work. The boundaries, colo denominations, and other information shown on any map in this work do not imply any judgment on the part of The World Bank concerning $t$ legal status of any territory or the endorsement or acceptance of such boundaries.

\section{Copyright Statement:}

The material in this publication is copyrighted. Copying and/or transmitting portions or all of this work without permission may be a violation applicable law. The International Bank for Reconstruction and Development/ The World Bank encourages dissemination of its work and normally grant permission to reproduce portions of the work promptly.

For permission to photocopy or reprint any part of this work, please send a request with complete information to the Copyright Clearar Center, Inc., 222 Rosewood Drive, Danvers, MA 01923, USA, telephone 978-750-8400, fax 978-750-4470, http://www.copyright.com/.

All other queries on rights and licenses, including subsidiary rights, should be addressed to the Office of the Publisher, The World Bank, 1818 
Street NW, Washington, DC 20433, USA, fax 202-522-2422, e-mail pubrights@worldbank.org. 


\title{
Strengthening Local Providers for Improved Rural Water Supply in Pakistan
}

\section{P131990 Final Output Synthesis Report}

\author{
mahmad1@worldbank.org \\ $5 / 6 / 2016$
}

This synthesis report details the process, outputs, intermediate outcomes, lessons learned and recommendations of the World Bank executed Technical Assistance (TA) on Strengthening Local Providers for Improved Rural Water Supply in Pakistan (P131990) implemented by the Water and Sanitation Program of the Global Water Practice. In particular this TA sought to assist the Government of Punjab (GoPunjab) to strengthen the accountability of service provision by communities to ensure improved access to rural water supply, particularly for the marginalized and poor. 


\section{TABLE OF CONTENTS}

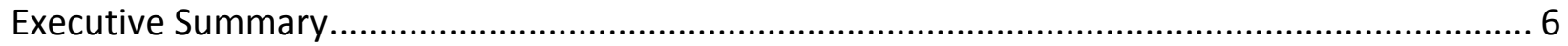

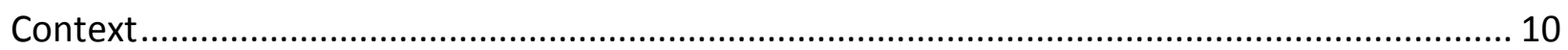

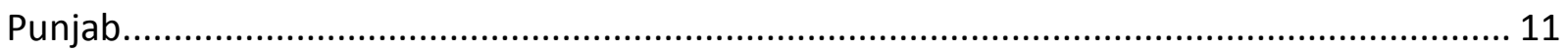

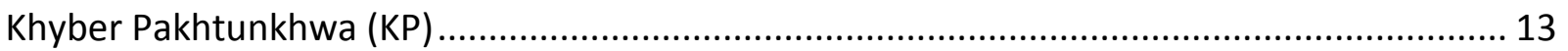

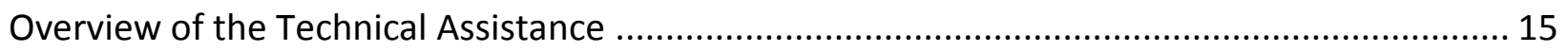

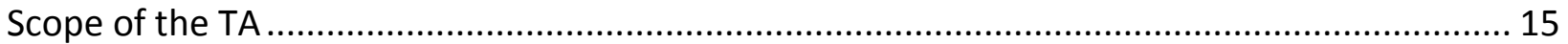

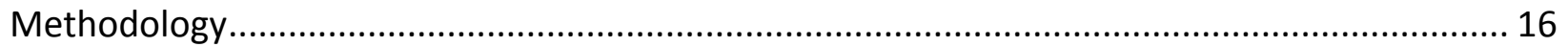

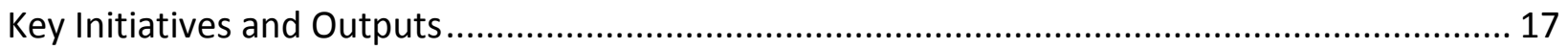

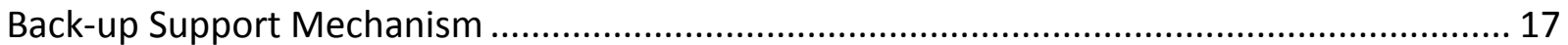

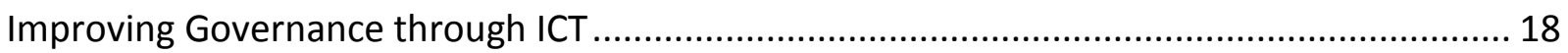

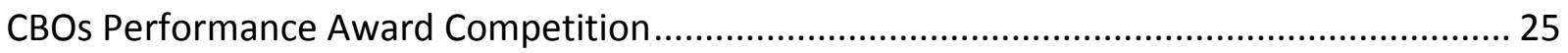

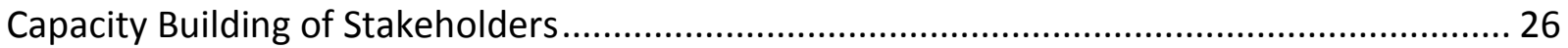

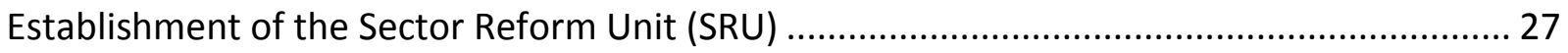

\section{OUTPUTS}

Annex A - Summary to CM on Sustainability of CBOs 11612

Annex B - Summary to CM on Sustainability of CBOs 16.02.16

Annex C- PHED Letter on Approval of Back-up Support

Annex D - GIS Dashboard for CBO Monitoring

Annex E - Analytical Reports on Status of Services by CBOs

Annex F - Training Report of PHED and CBOs

Annex $G-2^{\text {nd }} C B O$ Performance Award Competition

\section{FIGURES}

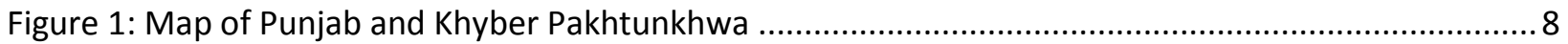

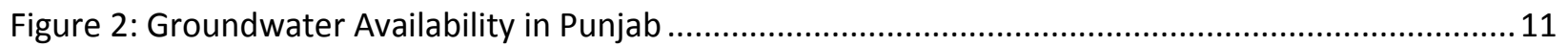

Figure 3: WATSAN Development Budget compared to the Provincial Development Budget in Punjab....12

Figure 4: Geo Tagging and Spatial Information Survey Mobile App ................................................... 19

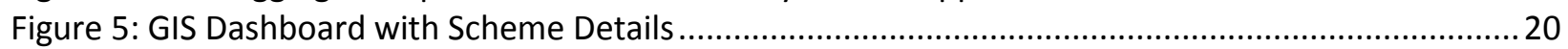

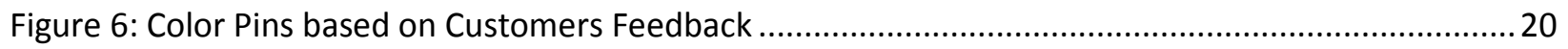

Figure 7: Status of RWS in Vehari District Based on Consumer Feedback .............................................2

Figure 8: Rural Water Supply GIS Dashboard with Pictures and Spatial Data ..........................................2 21

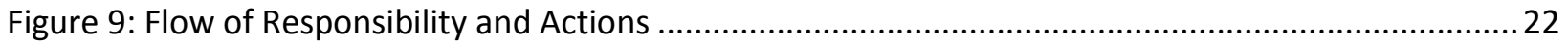

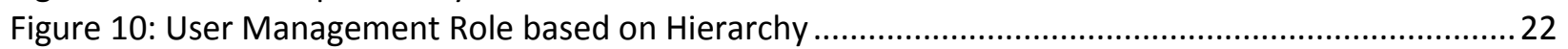

Figure 11: Tariffs, Numbers of schemes and Poverty Concentration in Six Districts.................................22

Figure 12: District Quality of Service Poverty Comparisons ................................................................ 24

TABLES

Table 1: Annual Construction of PHED Schemes in Punjab ............................................................... 12

Table 2: Failures of CBO Managed Rural Water Supply Schemes ............................................................17

Table 3: District-wise Details of Data Collected and Calls Made to CBOs...............................................20

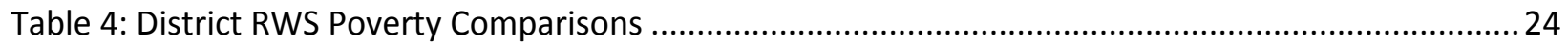

Final Output - Strengthening Local Providers for Improved Rural Water Supply in Pakistan (P131990) 
ABBREVIATIONS \& ACRONYMS

$\begin{array}{ll}\text { ADP } & \text { Annual Development Programme } \\ \text { BISP } & \text { Benazir Income Support Program } \\ \text { BCM } & \text { Billion Cubic Meter } \\ \text { C\&W } & \text { Communication and Works } \\ \text { CBOs } & \text { Community Based Organizations } \\ \text { CDU } & \text { Community Development Unit } \\ \text { CN } & \text { Concept Note } \\ \text { EOIs } & \text { Expression of Interest } \\ \text { GoPunjab } & \text { Government of Punjab } \\ \text { GDP } & \text { Gross Domestic Production } \\ \text { GIS } & \text { Geographic Information System } \\ \text { ICT } & \text { Information, communication technology } \\ \text { IVR } & \text { Interactive Voice Recording } \\ \text { JPM } & \text { Joint Monitoring Program } \\ \text { KP } & \text { Khyber Pakhtunkhwa } \\ \text { M\&E } & \text { Monitoring and Evaluation } \\ \text { MDG } & \text { Millennium Development Goal } \\ \text { MoU } & \text { Memorandum of Understanding } \\ \text { O\&M } & \text { Operation and Maintenance } \\ \text { OHR } & \text { Overhead Reservoir } \\ \text { PAC } & \text { Performance Award Competitions } \\ \text { PHED } & \text { Public Health Engineering Department } \\ \text { PRMP } & \text { Punjab Public Management Reform Program } \\ \text { RWSS } & \text { Rural Water Supply Schemes } \\ \text { SAP } & \text { Social Action Program } \\ \text { SRU } & \text { Sector Reform Unit } \\ \text { SMS } & \text { Short Messaging Services } \\ \text { SDC } & \text { Swiss Development Corporation } \\ \text { TA } & \text { Technical Assistance } \\ \text { TTL } & \text { Task Team Leader } \\ \text { UNICEF } & \text { United Nations Children's Emergency Fund } \\ \text { WASA } & \text { Water and Sanitation Agency } \\ \text { WSP } & \text { Water and Sanitation Program } \\ \text { WSSP } & \text { Water and Sanitation Service Peshawar } \\ \text { WB } & \text { World Bank } \\ & \\ & \end{array}$




\section{Executive Summary}

1. This synthesis report details the process, outputs, intermediate outcomes, lessons learned and recommendations of the World Bank executed Technical Assistance (TA) on Strengthening Local

Providers for Improved Rural Water Supply in Pakistan (P131990) implemented by the Water and Sanitation Program of the Global Water Practice. The development objective of this TA was to support the Government of Punjab (GoPunjab) in strengthening service provision by communities to ensure improved access to rural water supply, particularly for the marginalized and poor. These objectives were targeted through capacity building and introducing systems to better respond to community needs to manage rural water schemes via Community Based Organizations (CBOs).

2. The TA had four major components to improve the sustainability of community managed rural water supply schemes in the province of Punjab.

2.1 Back up Support Mechanism for CBOs: This TA designed a performance based support system for the 2,448 functional CBOs in Punjab to ensure that they can sustain their operations in the event of major technical failures. Support under this TA included the designing of the concept, qualifying criterion for $\mathrm{CBO}$ s to access to financial support for major repairs; listing of the qualifying expenditures (types of major repairs); development of the fiscal flows and the monitoring system. The GoPunjab subsequently approved this Back-up mechanism and allocated Rs. 250 M (US\$ 2.5 M) in FY 2014-15 to enable CBOs to finance major repairs of their water supply schemes. In FY 2015-16, the GoPunjab again allocated Rs. 500 M (US\$ 5.0 M) for this Back-up support mechanism.

2.2 Improving Governance through ICT: This TA supported the introduction of an ICT tool for seeking feedback from the customers of Rural Water Supply Schemes on the status of water service delivery. This TA designed, implemented and integrated within the PHED's Management Information System (MIS) a web based platform offering a mobile Short Messaging Services (SMS) and Interactive Voice Recording (IVR) to reach out to customers. This system was successfully piloted in 6 districts where 644 schemes were geo-tagged and 550,000 messages were sent to customers for feedback. The initiative GoPunjab is keen to scale up the system in the remaining 30 districts of the Province (covering over 2,200 CBO managed schemes) under an on-going Public Management Reform Program.

2.3 CBOs Performance Award Competition: This TA supported PHED in conceiving, designing and organizing three CBO Performance Award Competitions in the last three years. These CBO performance awards have evolved into a robust system for inviting applications (i.e. 2,800 CBO chairman are encouraged through an IVR to submit an Expression of Interest to enter this competition), shortlisting applications (through third party field verification of the top 2 CBOs in each District), identifying winners (through a 30 minute interview of CBOs by sector experts and crowd sources SMS based voting amongst the best performing CBOs). Based on the success of these events, PHED is expected make this part of its annual plan through budget allocations in the FY 2016-17 Annual Development Plan.

2.4 Capacity Building of Stakeholders: This TA undertook a training needs assessment of the CBOs and the Community Development Unit (CDU) of PHED in order to develop a tailor-made made training program for CBOs. Joint training sessions were organized for 100 PHED staff and 300 CBO members on the social, technical and financial management aspects of rural water supply schemes. Special emphasis was made to identify local champions - mostly within the CBOs - who were groomed to share their practical expertise with their peers. The training has been rolled out in the nine divisional circles of PHED. 
3. This TA supported the PHED of Khyber Pakhtunkhwa (KP) province to learn from the best practices of PHED Punjab. Following several meetings and field visits, support from this TA was requested for the designing and establishing of a "Sector Reform Unit (SRU)" in the PHED of KP. The SRU established as "think tank" - is fire walled from the implementation of any infrastructure projects with the mandate to carry out research and planning, capacity building and monitoring. The unit was subsequently established and functional as of December 2015 with a budget allocation of Rs. 60 M (US\$6.00 M) for the next three financial years (2016-2019).

4. This TA was primarily focused on the province of Punjab having a population of 100 million with of which 60 percent population live in rural areas. The policy and institutional interventions of this TA will benefit all of the 2915 functional CBOs of the province. The training program developed under this TA supported the building of the capacity of 300 CBOs and 100 PHED staff. The ICT based feedback mechanisms and the $\mathrm{CBO}$ monitoring system introduced under this TA covered $644 \mathrm{CBOs}$ in six pilot districts. The summary of the results of this TA are as follows:

\begin{tabular}{|c|c|c|}
\hline $\begin{array}{c}\text { Intermediate } \\
\text { Outcomes }\end{array}$ & Indicators & Achievements \\
\hline $\begin{array}{l}\text { Policy/ } \\
\text { strategy } \\
\text { informed }\end{array}$ & $\begin{array}{l}\text { - Revised standard MoU } \\
\text { between CBOs and PHED with } \\
\text { role clarity } \\
\text { - Back up supporting mechanism } \\
\text { for CBOs developed }\end{array}$ & $\begin{array}{l}\text { - Revised MoU finalized } \\
\text { - Back up support mechanism designed and } \\
\text { operationalized with US\$ 7.5 M commitments in } \\
\text { two years. } \\
\text { - Sector Reform Unit (SRU) established for R\&D, } \\
\text { monitoring and capacity building of PHED staff in } \\
\text { KP with a financial commitment of US\$ } 600,000 \text {. }\end{array}$ \\
\hline $\begin{array}{l}\text { Client } \\
\text { capacity } \\
\text { increased }\end{array}$ & $\begin{array}{l}\text { - Training conducted in } \\
\text { management, operations and } \\
\text { gender participation } \\
\text { - Monitoring system developed } \\
\text { to track status and quality of } \\
\text { services }\end{array}$ & $\begin{array}{l}\text { - Capacity built of over } 300 \text { CBOs and } 100 \text { PHED } \\
\text { staff in nine divisions of province } \\
\text { - Monitoring indicators developed and analytical } \\
\text { reports generated }\end{array}$ \\
\hline $\begin{array}{l}\text { Knowledge } \\
\text { deepened }\end{array}$ & $\begin{array}{l}\text { - CBOs \& PHED staff } \\
\text { incorporating learning from } \\
\text { exchange visits to improve } \\
\text { services } \\
\text { - District network of CBOs } \\
\text { established for lateral learning } \\
\text { and knowledge sharing }\end{array}$ & $\begin{array}{l}\text { - Four exposure visits of PHED and CBOs staff } \\
\text { organized. } \\
\text { - } 2 \text { District networks established. }\end{array}$ \\
\hline $\begin{array}{l}\text { Innovative } \\
\text { approaches } \\
\text { and solutions } \\
\text { generated }\end{array}$ & $\begin{array}{l}\text { - ICT solutions integrated to } \\
\text { monitor performance of CBOs } \\
\text { and feedback on services } \\
\text { - CBOs Performance Award } \\
\text { Competitions (PAC) } \\
\text { institutionalized in PHED } \\
\text { Punjab }\end{array}$ & $\begin{array}{l}\text { ICT based CBOs monitoring system integrated } \\
\text { into department MIS, scale up by WB operations } \\
\text { in FY } 17 . \\
\text { - } 2 \text { provincial CBOs PAC successfully organized } \\
\text { with partners } \\
\text { - Partnerships with donors like UNICEF in Punjab } \\
\text { and UNICEF \& SDC in KP were leveraged to } \\
\text { deliver results. }\end{array}$ \\
\hline
\end{tabular}


5. From inception, this TA was focused on institutional strengthening and sustainability. The Back-up support mechanism for CBOs and ICT monitoring of scheme performance are extremely significant initiatives to have been integrated into the government system. Both these mechanisms will continue to contribute to improvements in the performance and sustainability of rural water supply in Punjab.

6. Lessons learned in the strengthening of community based rural water service providers through the implementation of this TA are that:

- Community can deliver and sustain services to rural consumers provided they are treated as an equal partner, given the institutional space to deliver and held accountable;

- The recognition of $\mathrm{CBO}$ s role by

the government has sent a very positive signal to $\mathrm{CBO}$ s and community. CBOs realize that not only get recognition but will have access to government support for major repairs if they perform;

- Consistency in policy and the approach of government on the model(s) of service delivery is critical. Clear sectoral goals coupled with in-house arrangements based on the local reality and past experience can deliver integrated results that lead to institutional reform;

- Communication and respect towards all stakeholders enables the resources of development partners, the government and communities to be leveraged towards a common goal. Staring with interventions which are low cost and easy to apply increases the likelihood that these will deliver results and will be replicated by the different Figure 1: Map of Punjab and Khyber Pakhtunkhwa

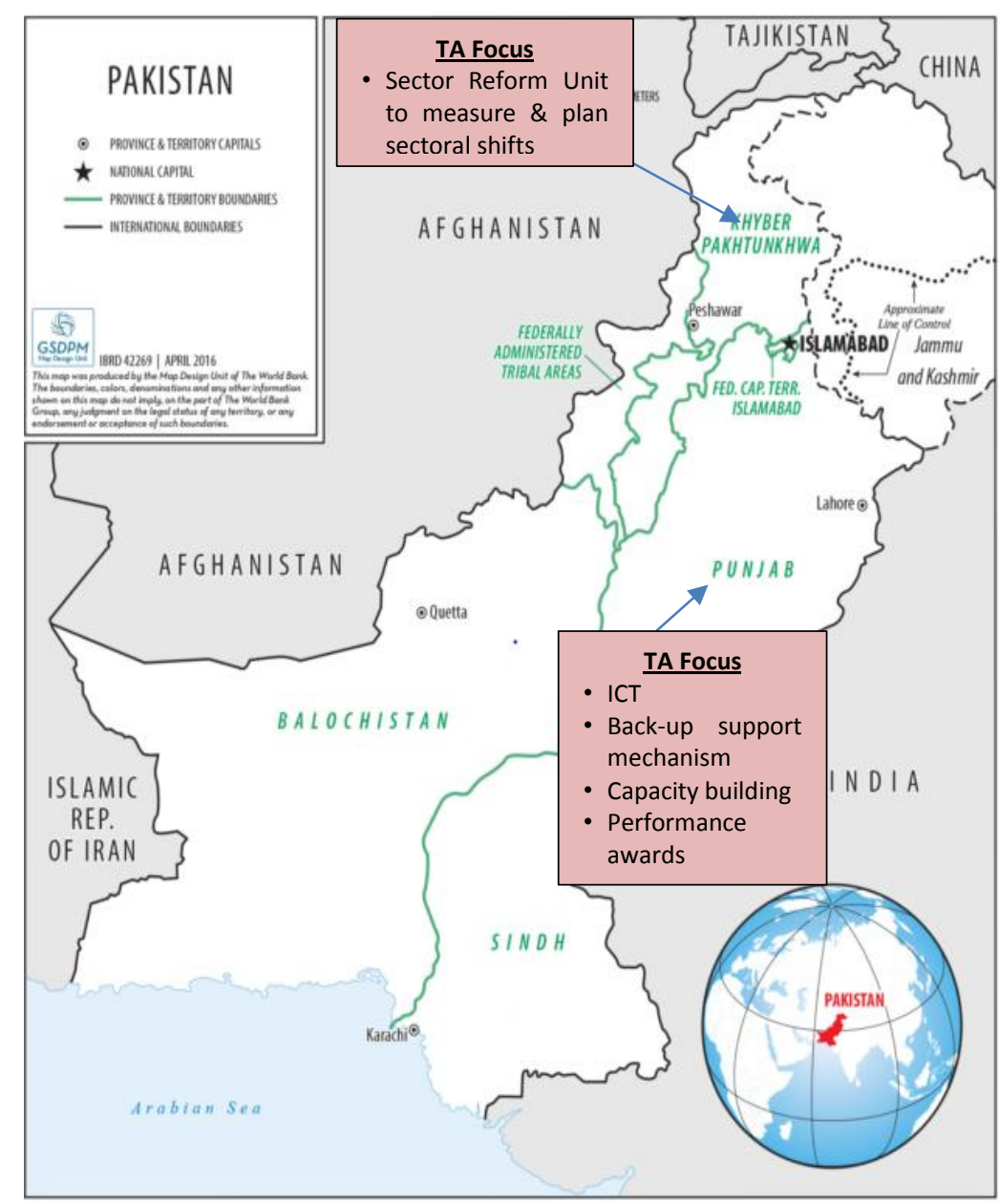
stakeholders.

7. Recommendations to sustain the service delivery improvements and institutional changes achieved through the extension of this TA are:

a. Punjab: should continue to support and build on the approach of providing rural water through a CBO managed system. Service quality, access and sustainability can be improved if the CBO management model is deepened further. Providing $\mathrm{CBO}$ s with a greater role in the rural water 
supply project cycle combined with a mix of training, networking and backstopping will generate the capacity necessary to deliver better services. To support this shift it is recommended that:

- A dedicated administrative backstopping facility (like the SRU of PHED in KP) is established to help with policy and legal reforms, tariff setting and metering, monitoring and evaluation, local and global research to assist in the planning of future sectoral changes;

- The community development unit (CDU) is restructured to proactively support CBOs in the management of their piped water systems. This would require the CDU to support the training of CBOs through the recording and disseminating of best practices. The CDU should develop the capacity to enhance the performance of $\mathrm{CBOs}$ in the Punjab and become a recognized knowledge resource on community based O\&M;

- A more formalized technical backstopping facility needs to be established that would proactively support CBOs in dealing with technical challenges in service delivery. This would range from advice on repairs and maintenance to major rehabilitations of systems;

- The scope of the CBO model be expanded to include the responsibility for identifying, designing and building rural water schemes. At present PHED is the lead agency in system development, and this can lead to disconnect with communities in terms of the appropriateness of the design and implementation of the scheme.

- $\quad A 2^{\text {nd }}$ generation management model has sprung up in Punjab where CBO member (individually or collectively) are taking over the management of schemes from other CBOs. This sub-contracting by CBOs to individuals or groups appears to be performing well but it is informal and doesn't have the backing of PHED. It is recommended that PHED assess and potentially strengthen this model thus offering an alternate to CBOs (who are not performing) and promoting an entrepreneurial culture in the water sector.

b. Khyber Pakhtunkhwa: should strengthen and mainstream the focus on the sustainable O\&M of rural water supply schemes. Service quality, access, and sustainability can be improved if providers have a greater role in RWS project cycles while at the same time they build their capacity through a mix of training, networking, and technical/administrative backstopping. To support this process is the following are recommended:

- The taking over the responsibility of the schemes transferred by PHED is leading to a deficit in trust between the CBOs and PHED. PHED needs to re-engage with the community in the planning, construction and post construction of rural water schemes to ensure sustainability and ownership. There is a need to explore models that could be effective in KP, ranging from community management of all O\&M to community support for PHED in service delivery;

- Sustaining the fire-wall of the SRU knowledge functions from the execution of projects is crucial to the success of the SRU. This means that the SRU should be supporting district PHED staff in the implementation of schemes and not implementing any infrastructure projects. Based on the analysis of the lessons from the field the SRU should take lead role in advising the PHED management in policy change and legal reforms, evaluation and planning, capacity building and monitoring. 


\section{Context}

8. Pakistan is the world's sixth most populous country, with a population of 191 million people and a projected population growth rate of 1.5\%. Total Gross Domestic Production (GDP) is US\$ 271 billion and per capita GDP is US\$1,427 (2015) placing Pakistan in the category of Middle Income Countries (>US\$1,215). Poverty is largely a rural phenomenon with 14 percent of the population living below the poverty line. Given the strong links between agricultural productivity, rural incomes and employment, agricultural water productivity has a high impact on growth and poverty reduction.

9. Pakistan is largely semi-arid, with average annual precipitation of less than $500 \mathrm{~mm}$ but with considerable year to year variation. The total average annual renewable water resource is 247 Billion Cubic Meter (BCM), of which 192 BCM is surface water and 55 BCM is groundwater. Nearly all of these resources are in international basins (primarily the Indus basin), and around four-fifths flow into Pakistan from upstream countries. Climate change is expected to reduce water security as a result of melting glaciers and more variable and intense rainfall, meaning water availability will be less predictable and floods and droughts more common, with impacts greatest for the poor.

10. Despite high population growth, Pakistan almost met the Millennium development Goal (MDG) target of 93\% access to an improved drinking sources (increasing from 86 percent in 1990 to 91 percent in 2015 as per Joint Monitoring Program data). During this period, 76 million people (8,300 people/day) gained access to improved water services (i.e. 4431 people/day in urban areas and 3936 people/day in rural areas). Despite these significant achievements, the drinking water supply in Pakistan is intermittent and the water quality is poor.

11. The 1973 Constitution assigned the water supply and sanitation subject to the provincial governments. In 2009, the Federal government approved a 'National Drinking Water Policy" and encouraged the provinces to prepare their provincial policies and strategies as per local resources, climate and situation. The role of the provincial government in water supply was further strengthened through the passing of the $18^{\text {th }}$ Constitutional Amendment in 2010. While most of the Provinces have retained the responsibility for policy provision, human resource management and financing, they have largely devolved the service delivery function to local government institutions through their respective Local Government Acts.

12. Pakistan has four provinces and each province has a PHED responsible for rural water supply. These PHEDs are full-fledged provincial departments headed by a Secretary as principal accounting officer. The post of Chief Engineer(s) is the highest technical position to whom the field formation report. The PHEDs have undergone several major changes over the last 5 decades:

- In the mid-1960's, the PHED's were established as highly professional organization for asset creation and handing over completed schemes to other authorities for O\&M,

- $\quad$ By the 1980's, the PHED's were also put in charge of O\&M. However, with tariffs not being adjusted to cover costs, the operating expenditures quickly overshot the operating budgets. The absence of financial and technical resources for O\&M then led to an increase in dysfunctional schemes. The rapidly deteriorating quality of rural water services and the steady rise in the number of failed schemes became an issue that warranted a paradigm shift in PHED's.

- In the early 1990's, the government embarked on the Social Action Program (SAP) with the support of the major donors, in health, education and water sector. The SAP focused on community involvement in social sectors to improve the long term sustainability of infrastructure. Under SAP the four provincial governments adopted a Uniform Policy for PHEDs 
(1994) which placed a greater role of beneficiaries in all aspects of scheme implementation (i.e. planning \& monitoring, community contribution of $4.5 \%$ of the capital cost and taking over of the responsibility for O\&M). The policy warranted all PHEDs to hand over completed schemes to beneficiary communities for O\&M.

13. Apart from achieving the desired objective of strengthened community participation it was envisaged that community management would free up more resources to invest in bridging the piped water access gap. However, the lack of support to communities in the financial and technical management of schemes compromised their operations resulting in a growing number of dysfunctional schemes. This then required reinvestments to replace dysfunctional schemes leading to a service delivery model best understood as one of build-neglect-rebuild.

\section{Puinjab}

14. Punjab is Pakistan's most populous provinces with a population pf 100 million. ${ }^{1}$ The Province is rich in both surface and ground water resources, due to the five rivers that pass through the province. This has given rise to a large irrigation network with enough leakage to provide a ground water recharge network. The province can be divided into four drinking water zones; i) sweet ground water zone (53\%) comprising of districts from central and southern parts; ii) brackish zone (29\%) mostly located in southern part; iii) mixed (brackish/barani) areas (13\%) comprising of southern and northern parts and iv) water scarce zone (5\%) mostly located in north in Potohar belt.

Figure 2: Groundwater Availability in Punjab

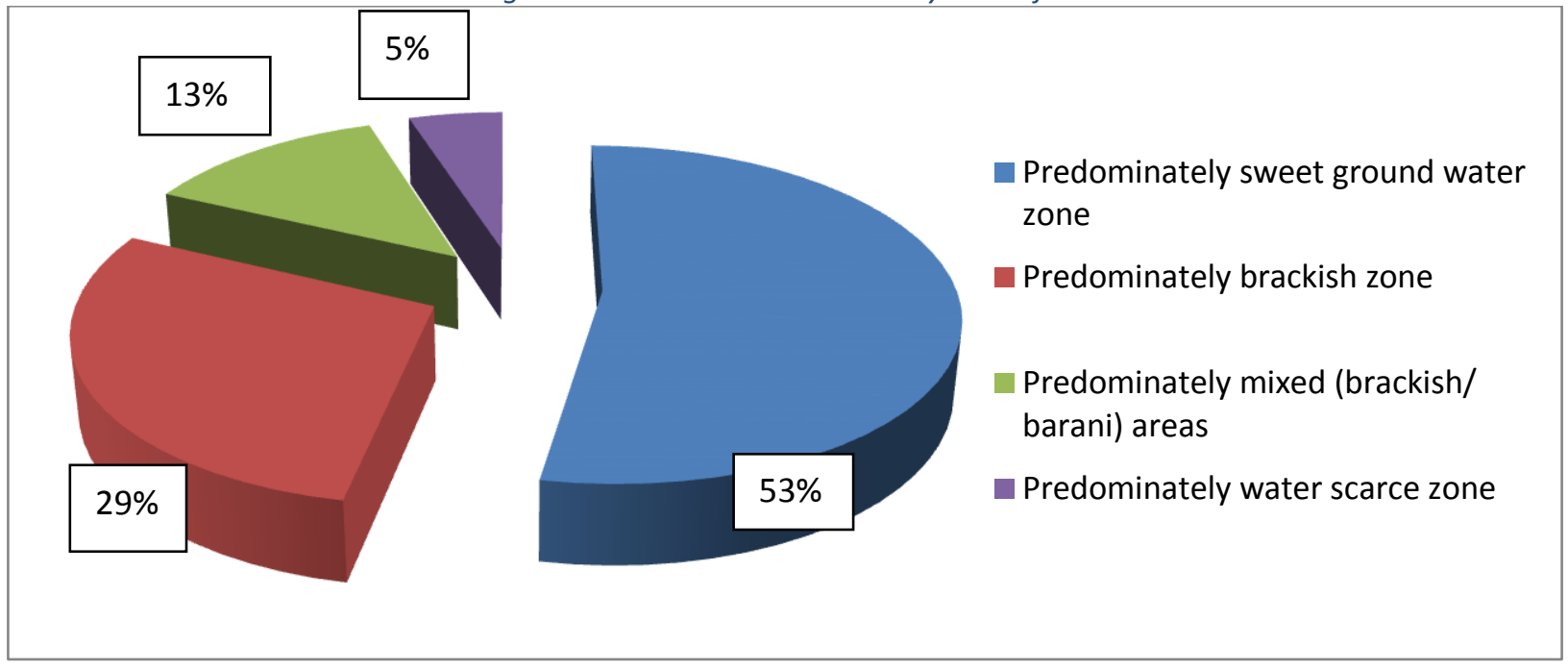

15. Access to water is extremely good with $95 \%$ of the population of Punjab having access to an improved water source ${ }^{2}$. The responsibility for water supply is assigned to the Water and Sanitation Agency (WASAs) in the five large cities, Municipal Committees in the in medium size towns and PHED in the rural areas. In 2011, the Provincial Cabinet approved a drinking water policy and recently the Province drafted a Municipal Water Act which is waiting for Cabinet's approval. This Act requires the government to establish a "Water Commission" to regulate the abstraction, quality of water services and pricing of water.

\footnotetext{
${ }^{1}$ Punjab Growth Strategy 2018, www.pndpunjab.gov.pk/economic_growth_strategy

2 PSLM survey 2013-14, http://www.pbs.gov.pk/sites/default/files//pslm/publications/pslm2013 14/A\%20report\%201314\%28\%2012-05-15\%29_FInal_1.pdf
} 
16. The financial allocation for the water sector is around $4 \%$ to $5 \%$ of total Annual Development Plan (ADP) of the government. This is very low as compared to the health and education budget allocations of $23 \%$ and $29 \%$ respectively in 2015-16 budget. The PHED allocation in 2008-09 ADP was $5.11 \%$; in $2009-10$ it was $4.99 \%$; in $2010-11$ it was $5.19 \%$ and in $2011-12$ it was $4.90 \%$.

Figure 3: WATSAN Development Budget compared to the Provincial Development Budget in Punjab

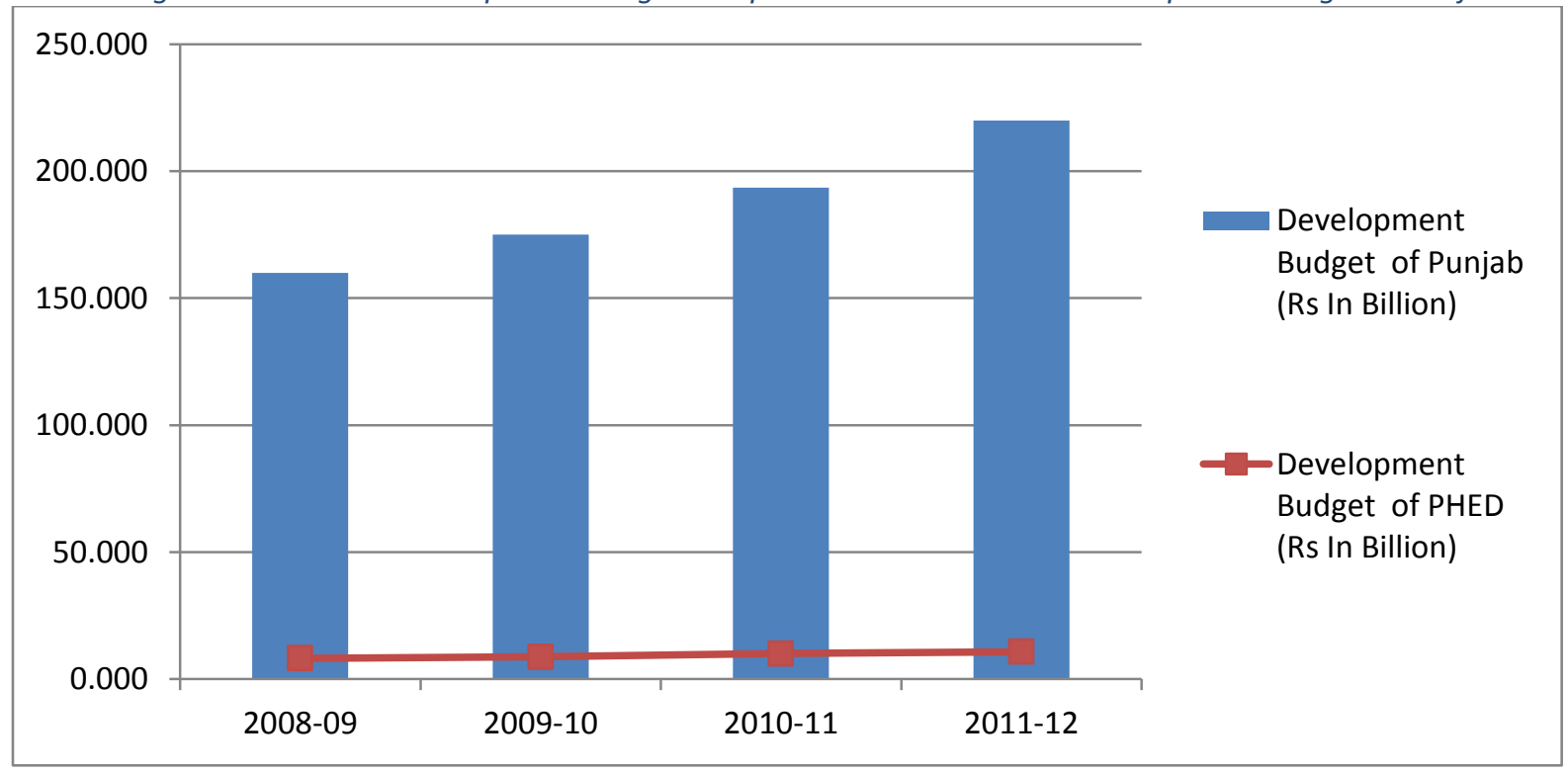

17. The Uniform Policy for PHEDs (1994) has not been implemented consistently across all four provinces. To date, Punjab is the only province which is still not allocating any O\&M budget for completed schemes which are the responsibility of beneficiary communities. As such, all 4,258 rural water schemes constructed by PHED in Punjab have been handed over to communities for O\&M.

Table 1: Annual Construction of PHED Schemes in Punjab

\begin{tabular}{|l|r|}
\hline \multicolumn{1}{|c|}{ Year } & Schemes constructed \\
\hline $1970-75$ & 31 \\
\hline $1975-80$ & 98 \\
\hline $1980-85$ & 297 \\
\hline $1985-90$ & 752 \\
\hline $1990-1995$ & 753 \\
\hline
\end{tabular}

\begin{tabular}{|c|r|}
\hline \multicolumn{1}{|c|}{ Year } & Schemes constructed \\
\hline $1995-2000$ & 542 \\
\hline $2000-2005$ & 475 \\
\hline $2005-2010$ & 752 \\
\hline $2010-2015$ & 558 \\
\hline Total (1970-2015) & $\mathbf{4 2 5 8}$ \\
\hline
\end{tabular}

18. A typical PHED tube well based scheme designed for a single village serves 150 to 200 households; on average and costs Rs. $17,500,000$ to $20,500,000$ (US\$175,000 to 205,000). The pump house, rising main, overhead reservoir and distribution network are main components of scheme and their specifications varies depending upon the water source and population. In many cases, land is donated by the community as well as a commitment to take over O\&M of the schemes once they are completed.

19. The Punjab PHED is catering to the water needs of nearly $32 \%$ of the province's 60 million rural inhabitants. The PHED has a Community Development Unit (CDU) responsible for social mobilization of communities at the various stages in the implementation of schemes. The unit staff interact with 
CBOs which enter into an agreement with PHED through a Memorandum of Understanding (MoU) to undertake the responsibility of O\&M of the schemes. The MoU clearly indicates that PHED will not bear any operational cost and that the CBOs will be responsible for all repair and maintenance costs. The $\mathrm{CBOs}$ generate revenue primarily through the recovery of water charges from consumers with the average tariff ranging from Rs. 70 - 300/month (US\$0.70-3.00).

20. As CBOs are responsible for O\&M costs (i.e. electricity bills, operational staff salaries and repair) and therefore no recurrent cost (for schemes) is earmarked in the PHED budget. The major portion of the PHED budget is spent on the development of new schemes and the rehabilitation of dysfunctional schemes. The growing number of dysfunctional schemes eventually caught the attention of PHED management. Since there was no provision in the MoU for PHED to support CBOs in major repairs the only option was to take the schemes under the rehabilitation category. This means that every year the PHED would undertake rehabilitation of some of the dysfunctional schemes (depending on budget envelope) as part of the annual development program. This means that it takes at least one year (as the ADP cycle is one year) before the PHED could rehabilitate a dysfunctional scheme. In the meantime the community will switch to alternative (mostly unimproved) sources and the CDU will have to re-organize the $\mathrm{CBOs}$ again once the schemes is rehabilitated.

21. Punjab CBOS are operating as a body corporate (i.e. fully independent in managing their own affairs in regards to tariff setting, service timings, disconnection policies \& subsidies to poor customers). In the case of the tariff, the policy requires "full cost recovery + emergency savings" from the customers. The tariff should cover the electricity cost, operational staff cost, O\&M cost, repairs and a portion of savings to meet emergency operations. This requires sound financial management and all CBOs are encouraged to establish a joint account managed by the $\mathrm{CBO}$ office bearers. CBOs are however accountable to the PHED for their performance and quality of operations. As per the MOU, the CBOs have to submit a periodic report on their operations and financial management.

22. CBOs are accountable to PHED for performance and operations. As per MOU CBOS have to submit a periodic report on operations, financial and other matters. LG system in Pakistan had a gap from 2009. New LG elections took place in December 2015 but the elected councilors have yet to start their functions.

23. PHED Punjab requested WB Technical Assistance in carrying out a diagnostic study to identify the root causes of $\mathrm{CBO} /$ scheme failures and to propose long term recommendations for improving the sustainability of CBO managed schemes. The details of this technical assistance including the process, results and lessons are discussed in next section of this report.

\section{Khyber Pakhtunkhwa (KP)}

24. Khyber Pakhtunkhwa (KP) accounts for an estimated 10.5 percent of the country's GDP and about 14 percent of the population. KP's population was 27.2 million in $2012^{3}$ with 83 percent residing in rural areas with the capital Peshawar housing an estimated 2.2 million people. The population density in 2014 was 345 persons per square kilometer having more than doubled over the last 30 years. ${ }^{4}$

\footnotetext{
${ }^{3}$ Volume II, table 1.1, data from Pakistan census bureau website, http://www.census.gov.pk.

${ }^{4}$ Source, Government of Khyber Pakhtunkhwa website, http://www.khyberpakhtunkhwa.gov.pk/aboutus/Area-Population.php.
} 
25. KP is arguably the most crisis-affected province in Pakistan. Due to its proximity and close cultural ties to Afghanistan, KP has suffered from the fallout of the conflict in Afghanistan. This has given rise to a precarious security situation as well as a prolonged period of political and social instability. The influx of three million Afghan refugees over the past two decades (1.8 million of whom are still living in KP) has intensified the demographic pressure of a rapidly increasing population, placing additional strain on the province's resources. The Afghanistan conflict has also exacerbated local extremism, leading to hostilities between militants and Pakistan's security forces. This has far-reaching consequences on economic activity and has inflicted extensive damage on livelihoods, private property and public infrastructure.

26. The institutional responsibility for water service provision in the province is evolving with changes to the local government system. It is currently the case that the responsibility for water service provision lies with the Water and Sanitation Service Peshawar (WSSP) $)^{5}$ in capital of the province, the TMAs in the small and medium size towns and the PHED in the rural areas of KP Province. Access to piped water supply in the province was 31 percent in 2013-14 reflecting a significant decline from the 41 percent in 2011-12. This decline in use of tap water in offset by an increase in access to motorized pumps and springs ${ }^{6}$.

27. KP PHED has completed 4,110 drinking water supply schemes with a capital cost of about Rs. 10.00 billion (US\$100 M). Out of this, 1,682 schemes were completed prior to SAP, 992 schemes were completed under SAP, while the remaining 1,436 schemes were completed after SAP. Out of the above mentioned total 4,110 schemes, 2,748 are pumping based while 1,362 schemes are gravity based. The SAP had a mixed results in KP and PHED could not continue with Uniform Policy for PHEDs (1994) due to the political resistance to the community managed rural water model.

28. Under the Devolution Plan of 2001 the PHE Department was merged with the Provincial Communication and Works (C\&W) Department. During 2001-2009 the creation of rural water schemes dropped substantially as PHE was an attached department and the bulk of the funding of C\&W was earmarked for building and roads. In 2009 PHE was re-established as independent department for provision of rural water and drainage services in the province. Slowly and gradually the PHED has rebuilt its human and financial commitments. In 2011, the PHED started taking over the O\&M of all of the community managed schemes. At the time of preparation of this TA it was envisaged that the PHED of KP will be exposed to the best practices of Punjab especially in regards to the support for the community management model. The support extended under this TA to KP PHED its process, results and lessons are discussed next sections of this report.

\footnotetext{
${ }^{5}$ WSSP is a corporately governed utility delivering municipal services in urban areas of the capital city of Peshawar.

${ }^{6}$ http://www.pbs.gov.pk/sites/default/files//pslm/publications/pslm2013_14/A\%20report\%2013-14\%28\%2012-05-15\%29_FInal_1.pdf
} 


\section{Overview of the Technical Assistance}

29. Like many other infrastructure departments the focus of Punjab PHED has been on "asset creation" rather than "service delivery". In the absence of strong monitoring \& evaluation mechanisms, the department was mot internalizing the field lessons into its planning processes. While the department continues to construct approximately 70 new water supply schemes and rehabilitate roughly 100 schemes each per year under the ADP, as many of the functional schemes were becoming dysfunctional. Although the department has a community development unit with field based male and female staff, the focus of unit's activities has only been on community formulation for the creation of new schemes rather than continuous support to the CBOs undertaking the O\&M of existing schemes.

30. Punjab PHED had a long history of working with CBOs but was struggling to maximize the potential of $\mathrm{CBO}$ s to achieve the desired service delivery results (i.e. sustainable rural water supply operations). The increasing number of dysfunctional schemes and lack of capacity of CBOs were the main challenges which the PHED has been facing since early 2010. The GoPunjab therefore approached the World Bank seeking support to; a) strengthen the managerial, technical and social support to $\mathrm{CBOs}$; and b) develop a system to ensure the sustainability of $\mathrm{CBO}$ managed schemes.

31. This TA was in line with the GoPunjab Drinking Water Policy 2011 emphasizing the strong engagement with communities at every stage in the implementation of rural water schemes (i.e. from planning, to construction, to $O \& M$ ). Under the policy the GoPunjab has committed not only to reach out to the unserved population but also to strengthen community management models by addressing crucial bottlenecks and weaknesses. The policy also emphasized improvements in the monitoring of schemes handed over to communities and the integration of innovative approaches to build the capacity of both community and government officials. This TA sought to contribute to the commitments of the GoPunjab to achieve these policy objectives.

\section{Scope of the TA}

32. Strengthening the sustainable delivery of rural water services in the Punjab Province was the main target of this TA for which interventions both at policy/institutional level and grass root level were designed and implemented. The main components of the TA and results are described below:

32.1 Back-up Support Mechanism: This TA supported Public Health Engineering Department (PHED) GoPunjab to design and implement a framework to assist well-performing CBOs to sustain the Operation and Maintenance (O\&M) of their schemes. The purpose of the Back-up support mechanism (the first of its type in the rural water sector in Pakistan) is to ensure that the 2,800 plus $\mathrm{CBO}$ s who are successfully managing their rural water supply schemes having met $100 \%$ of the electricity charges and operational staff salaries are able to access the financial resources necessary major repairs. Analysis undertaken through this TA revealed many schemes becoming dysfunctional when they developed major faults. As per the existing Memorandum of Understanding (MoU) with PHED the CBOs were fully responsible for the O\&M of schemes to the extent that PHED did not have any provision to extend any financial support for these transferred schemes.

32.2 Improving Governance through ICT: This TA sought to extend support for the introduction of an ICT tool for seeking feedback from the beneficiaries of water service delivery rather than relying on PHED or $\mathrm{CBO}$ feedback. This required the development and integration of a web based platform offering mobile access to beneficiaries to gain feedback on the status of schemes and the performance of CBOs. This should enable provincial government (office of the 
Chief Secretary and Chief Minister) access to the dashboard to obtain updates on the status of schemes without relying on PHED information.

32.3 СBO Performance Award Competition: This TA sought to support the PHED to develop a system to a) infuse a positive spirit of competition among CBOs to improve services and $b$ ) provide a platform for networking and peer learning. This required the development of a system for the identification, short-listing and selection of the best performing CBOs. This also required the development of means to enable CBO members to exchange expertise with each other.

32.4 Capacity Building of Stakeholders: PHED has a dedicated social mobilization unit with field based male and female staff. The Community Development Unit is responsible for social mobilization activities before the start of rural water supply schemes, during the construction of schemes and in the post hand-over phase. In reality, however CDU interaction with communities diminish as schemes become older. The capacity building component of this TA focused on capacity assessment and subsequently capacity enhancement of CBOs and CDU staff to improve the technical, financial and social management associated with sustaining rural water supply schemes.

\section{Methodology}

33. The methodology for the implementation of this TA was inclusive, result oriented and focused on institutionalization rather a standalone "project activity". The client (PHED), CBOs and development partners (UNICEF) were consulted at every stage of the TA. A workshop was even organized with the stakeholders in which the objectives of TA were shared, seeking partnership and guidance in the implementation of this TA. All the initiatives of the TA were designed by the TTL and team, with the active support of the client and partners. Analytical pieces and idea papers were developed for each of the components that were then implemented following the approval of the GoPunjab. Firms were hired for specialized tasks (including field based activities) based on TORs that were shared with the client, their comments incorporated and their facilitation sought. As per the TORs the firms shared their strategy, plan and methodology of implementation with all stakeholders to build partnerships and consensus on the approach. Inclusive consultations were also organized by the firms to share their findings from field, the details of their proposed intervention and their tests of the results. Like the ICT firm organized three consultative sessions - in $1^{\text {st }}$ it shared the methodology, in $2^{\text {nd }}$ it shared the design of the web cum SMS cum IVR system and in last session the early findings from field were shared with stakeholders. Similarly the "Capacity Building" firm also shared it training plan and training material with stakeholders before imparting training activities in field. Two initiatives under this TA (i.e. the ICT and capacity building) were implemented by firms while the rest were implemented by the TTL and team.

34. Another key aspect of the methodology was the involvement of the client in the implementation of TA initiatives. In case of ICT initiative, CDU staff geo tagged the 644 schemes in the field using a purpose built mobile application. The CDU staff were trained by the hired firm in use of the mobile app through class room and field trainings. The firm undertook the validation and cleaning of the data collected by CDU while also performing a backstopping and troubleshooting role. The CDU staff collected over 113,990 mobile numbers of the beneficiaries of the 644 tube wells through a mobile based field survey. The active involvement of the staff of the CDU in the pilot initiative not only built the capacity of client but also enabled them to replicate and scale up the initiative without external funding. In the case of the capacity building contract, the firm not only involved the technical and $\mathrm{CDU}$ staff but also CBOs members as resource persons. This not only promoted peer to peer learning amongst $\mathrm{CBO}$ members and CDU staff but also provided a much needed boost to the confidence of the $\mathrm{CBO}$ s and the $\mathrm{CDU}$. 


\section{Key Initiatives and Outputs}

\section{Back-up Support Mechanism}

Outputs:

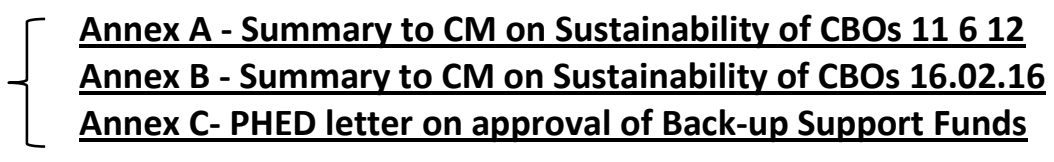

35. The Back up support system was designed and operationalized through an intensive process that included field assessments and diagnostics work to ascertain "why schemes fails" and "what would it take to sustain them". In order to ascertain the status, causes and type of failure of schemes a third party assessment supervised by the district administration was carried out of all 4,258 rural water supply schemes. This assessment identified that 1,343 schemes (or $33 \%$ of the total number of schemes) were dysfunctional categorizing the schemes according to the cause of failure.

Table 2: Failures of CBO Managed Rural Water Supply Schemes

\begin{tabular}{|c|c|c|c|}
\hline Number & Category/Type of failure & $\begin{array}{l}\text { Numbers of } \\
\text { schemes }\end{array}$ & $\begin{array}{l}\text { Percentage of total } \\
\text { dysfunctional schemes }\end{array}$ \\
\hline 1 & Source failure & 342 & $25.47 \%$ \\
\hline li & $\begin{array}{l}\text { Major defects in machinery / rising } \\
\text { main / distribution network }\end{array}$ & 323 & $24.05 \%$ \\
\hline lii & $\begin{array}{l}\text { Non-payment of WAPDA dues / } \\
\text { Disconnection. }\end{array}$ & 227 & $16.90 \%$ \\
\hline IV & $\begin{array}{l}\text { Theft of major components like electric } \\
\text { motor, transformer etc. }\end{array}$ & 116 & $8.64 \%$ \\
\hline \multirow[t]{2}{*}{ V } & $\begin{array}{l}\text { Non-payment of WAPDA dues / } \\
\text { Disconnection. }\end{array}$ & 335 & $24.94 \%$ \\
\hline & Total & 1343 & $100 \%$ \\
\hline
\end{tabular}

36. Analysis of the data showed that $49 \%$ of the dysfunctional schemes are not operating due to technical faults, $26 \%$ of the dysfunctional schemes have gone out of operation due to weak financial capacity in maintenance and $25 \%$ of the dysfunctional schemes have stopped operating due to managerial / social reasons amongst the beneficiary communities. The diagnostic further showed that the focus on asset creation, the absence of an M\&E wing, the lack of interaction with beneficiaries (especially post hand over stage), the capacity constraints of both PHED and CBOs, the lack of a back-up support mechanism (for major repair) and the absence of any incentives for $\mathrm{CBOs}$ to perform were the major factors contributing to the failure of $\mathrm{CBOs}$ and schemes.

37. The field data also revealed that there are many schemes which are dysfunctional due to major technical issues requiring the deepening of bore wells, the re-winding, repair and replacement of electric motors, transformers and pumps. These major repairs were estimated to cost between Rs. 0.5 - 2 million (US\$5,000-20,000). This requires an additional household contribution of between Rs. 2,500-10,000 (US\$25 - US\$100) to the CBOs which are managing these schemes on a cost recovery and user pays basis. This (contribution) is well beyond the capacity of poor households in Punjab who are willing to pay the monthly tariff of Rs. $70-300$ (US\$ 0.70-3.00) but unable to pay US\$ 25-100 for major repairs. As a result, major repairs costing as low as US $\$ 5,000$ led to the 
abandoning of some schemes by $\mathrm{CBO}$ s when households were unwilling to contribute and PHED had no mechanism to respond to such incidents.

38. Although PHED has a time consuming process of reflecting dysfunctional schemes under the annual development program and finally repairing it, the communities which needed water on a daily basis were forces to switch to alternate mostly unimproved sources. As PHED has limited funds and as the cost for rehabilitation increases as schemes are left in a dysfunctional state, it is not possible for every dysfunctional scheme to be rehabilitated through the ADP.

39. This TA supported the identification of the root causes of dysfunctional schemes and worked on the establishment of a mechanism to sustain the services delivery focusing on occurrences when less than 1 to 5 percent of the capital cost is required to repair dysfunctional schemes.

40. The development of a back-up support program was based on inclusive consultations with the client and $\mathrm{CBO}$ s at all levels. Field surveys and data analysis were used to evaluate various options for the extension of back-up support. This process led to formulation of comprehensive back up support mechanism presented by the department and approved by Chief Minister of Punjab province as follows:

- Establishment of Rs. 250 M (US\$2.5 M) back-up support fund with approximately Rs. 100,000 (US\$1,000)/- per scheme per annum for a total 2,448 functional schemes

- The fund is only authorized for major breakdown repairs including the development of a new source, the replacement of damaged mains, pumps, transformers, motors etc.

- CBOs will cover routine O\&M as per MoU and will not use this fund for O\&M

- Only CBOs that fulfill certain performance criteria (i.e. full cost recovery from users, no electricity bill arrears, up to date records) will be eligible to access support from this fund

41. Of the Rs. $250 \mathrm{M}$ (US\$2.5 M) budget allocated by the finance department of GoPunjab in FY 201415 , only Rs. $61 \mathrm{M}$ (US\$0.6 M) was released with the rest of the funds lapsing in the government system. In FY 2015-16 the GoPunjab made a budget allocation of Rs. 871 M (US\$ 8.71) for this initiative. The department has developed a process of transferring the funds through to the district office. A district committee of PHED field staff and district administration has also been established in every district to ascertain whether the CBOs qualify on above criterion or not. So far 1,684 CBOs have opened the requisite joint (CBO chairman and PHED engineer) accounts.

\section{Improving Governance through ICT}

Outputs:

Annex D - GIS Dashboard for CBO Monitoring Annex E - Analytical Reports on Status of Services by CBOs

42. The density of mobile phones has grown enormously in Pakistan from 3.4 percent in 2003 to 79.8 percent in December 2015. Smartphone penetration has grown at a steady pace from 13 percent in January 2013 to 31 percent by January 2015. Telecom has become the fastest growing sector in Pakistan in the last five years. Pakistan is the fifth largest country in terms of the usage of mobile phones with 139.9 million subscribers out of 185 million population. This TA internalized the mobile phone based applications as they offered considerable opportunities to improve the performance of community managed water supply schemes in rural Punjab. 
43. Information and communications technology (ICT) has transformed many sectors in Pakistan and is rapidly changing how people communicate. Consumer banking and consumer industry has internalized various aspects of ICT to communicate with consumers. For the rural poor, the ICT sector in Pakistan also offers many low cost applications like mobile SMS, Interactive Voice Recording (IVR) calls, social media sites, e-learning platforms, user-friendly cameras and georeferencing maps. Till now the potential of ICT has remained largely untapped in the rural water sector in Pakistan.

44. The ICT integration in PHED is part of a large province wide ICT program (funded by World Bank) which has successfully demonstrated results like reduction in corruption; improved efficiency of officials; improvement in services in health; education; domicile; police reporting; driving license and court cases in Judiciary.

45. This TA has piloted the ICT integration in rural water supply in Punjab with the objective of improving governance to impact the sustainability of schemes and continuity of services. It was proposed that a strong oversight mechanism using ICT tools will strengthen the ability of the government to ensure that the public sector investments in rural water sector are delivering services. In Punjab province, where community participation in rural water sector is the strongest amongst the four provinces, this TA has capitalized on this by deploying mobile technologies to obtain feedback from the beneficiaries rather than the service providers. This has sends a message to CBOs and PHED field staff that they are accountable for their performance.

46. Several meetings were held with PHED staff and select CBOs to agree on the theory and assumptions associated with the approach, to finalize the tools and modalities for mobile based monitoring. Six pilot districts were selected in consultations with the client, three which were relatively well-off (Faisalabad, Gujrat and Chakwal) and three Figure 4: Geo Tagging and Spatial Information Survey Mobile App districts with poorer social indicators (R.Y Khan, Vehari, and Kasur). Existing PHED data revealed a total of 700 schemes in these six districts. A tailor made mobile application was then developed for geo tagging and uploading spatial information of all functional schemes in these six districts. The data revealed that there are total 644 schemes (not 700 as per PHED data) of which 608 were functional. All of the spatial data (i.e. photos, videos) were uploaded on the GIS map with the 608 geo tagged schemes. PHED staff was
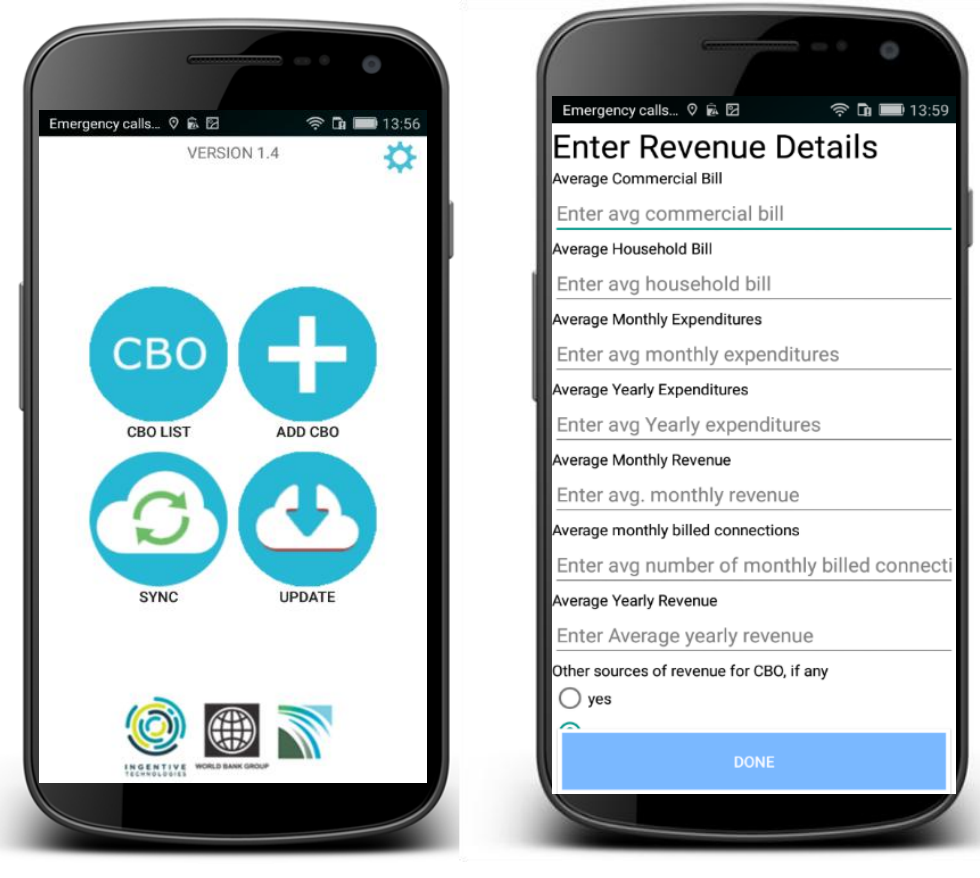
trained in geo tagging as part of capacity building of client. 
47. The PHED staff also collected data about number of connections in each scheme through meetings with CBO staff and searching through CBO records. A total of 140,479 connections were recorded in 6 districts against 608 functional schemes. PHED staff also collected the mobile numbers of all beneficiaries of the 608 functional schemes through corner meetings and house to house surveys. In this exercise 113,990 cell numbers of beneficiaries were collected. A one minute voice message of the PHED Minister was recorded and sent to all 113,990 mobile numbers to inform them about this initiative of PHED seeking their co-operation. This IVR call was relayed twice to sensitize community to this PHED initiative and inform them about their role in service delivery.

Table 3: District-wise Details of Data Collected and Calls Made to CBOs

\begin{tabular}{|c|c|c|c|c|}
\hline Name of District & Schemes & Connections & Cell numbers & SMS and IVR Calls \\
\hline Vehari & 80 & 15,019 & 13,245 & 79,876 \\
\hline Chakwal & 95 & 31,477 & 25,678 & 125,980 \\
\hline Gujrat & 113 & 25,973 & 20,908 & 91,987 \\
\hline R.Y.Khan & 139 & 24,688 & 18,109 & 79,865 \\
\hline Kasur & 89 & 22,318 & 18,064 & 102,987 \\
\hline Bahawalpur & 128 & 21,004 & 17,986 & 69,876 \\
\hline Total & 644 & 140,479 & 113,990 & 550,571 \\
\hline
\end{tabular}

48. A seamless open source dash board was developed on which all the features were uploaded and geo tagged. The dashboard was configured in such a manner as to enable:

- All water schemes of six districts to be viewed on google maps with their actual locations;

- Photographs of all scheme assets (pump house, OHR, office, rising main) to be viewed

- The functional status of each scheme to be viewed as per consumers feedback

- Technical, social and financial management details of each scheme to be viewed

- The GIS base dashboard to be updated remotely from an android mobile application

Figure 5: GIS Dashboard with Scheme Details

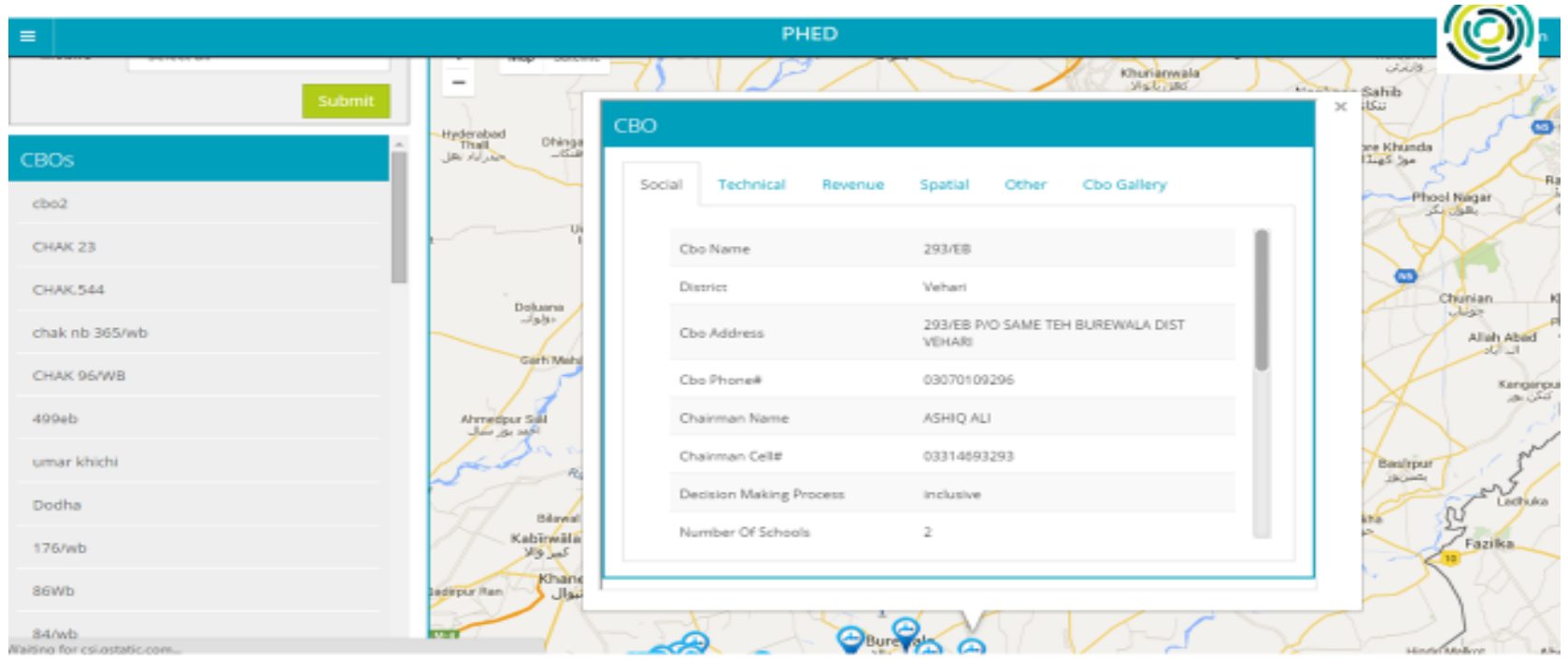

49. Over a period of 6 months over 550,571 SMS and IVR calls were made to the cell numbers of beneficiaries to ascertain the status of schemes. In the $1^{\text {st }}$ week of every month a simple system generated question was sent to all numbers asking a question 
"whether your scheme was functional last month". Households were requested to reply by pressing 1 for "yes" and 2 for "no". On the basis of feedback of beneficiaries the system calculated the percentage of "yes" and "no" and assigned operational status colors to each scheme.

- Red (Dysfunctional): less than 30\% of consumers responded with "yes"

- Green (Functional): more than 70\% of consumers responded with "yes"

- Yellow (border-line): is border line where $31-70 \%$ of consumers responded with "yes".

Focus of the PHED is primarily on the yellow schemes to save schemes from turning "red" in next survey. The color coded schemes on the google map also enables the overall performance of CBOs and PHED to be assessed. More green schemes meaning that the majority of schemes are functional while more red shows a district in trouble.

Figure 7: Status of RWS in Vehari District Based on Consumer Feedback

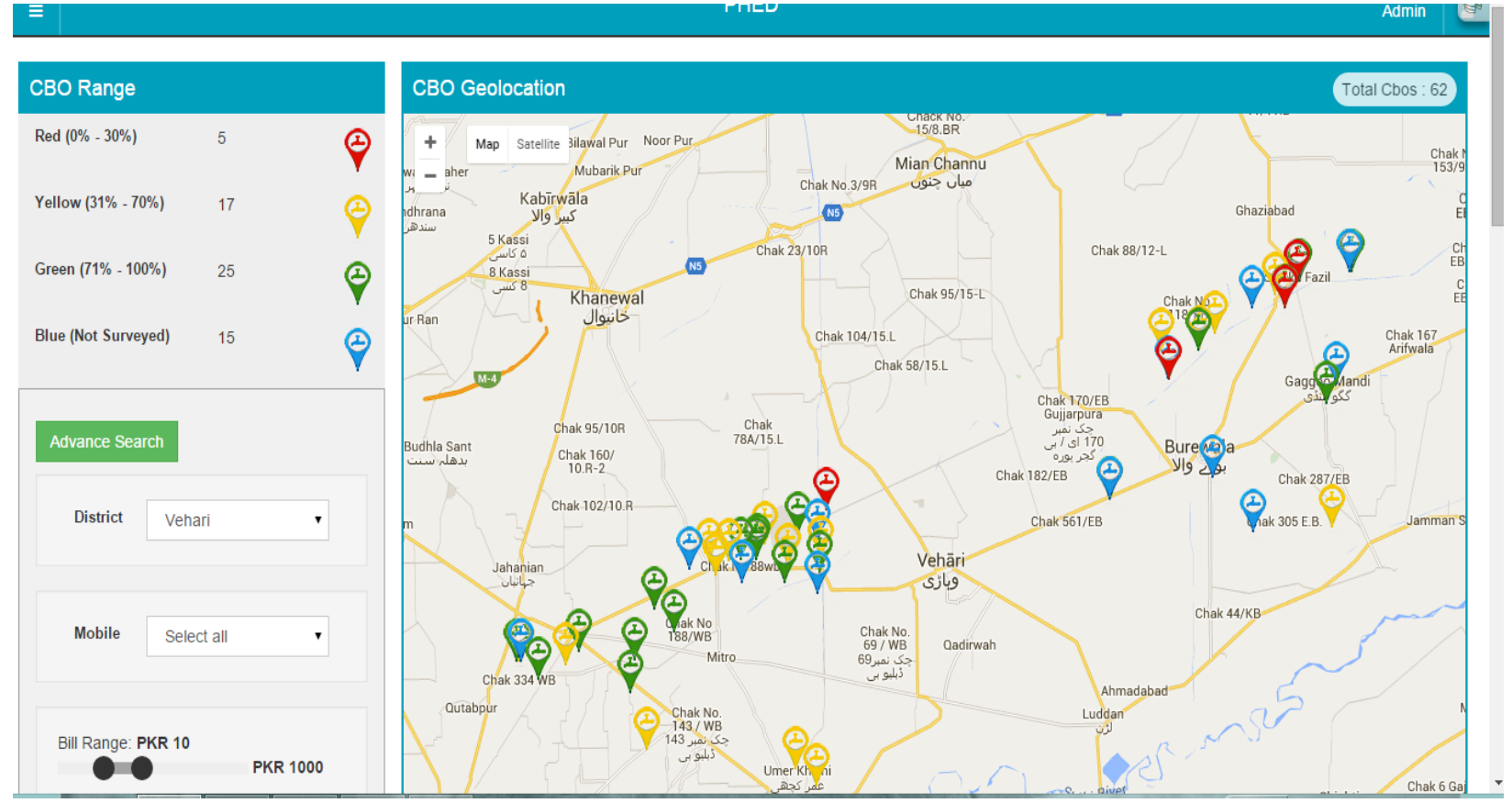

50. By clicking on any scheme on the map one can find all the spatial information about the schemes in three categories (i.e. technical, financial and management). The PHED staff were trained to update the data in the system on periodic basis.

Figure 8: Rural Water Supply GIS Dashboard with Pictures and Spatial Data

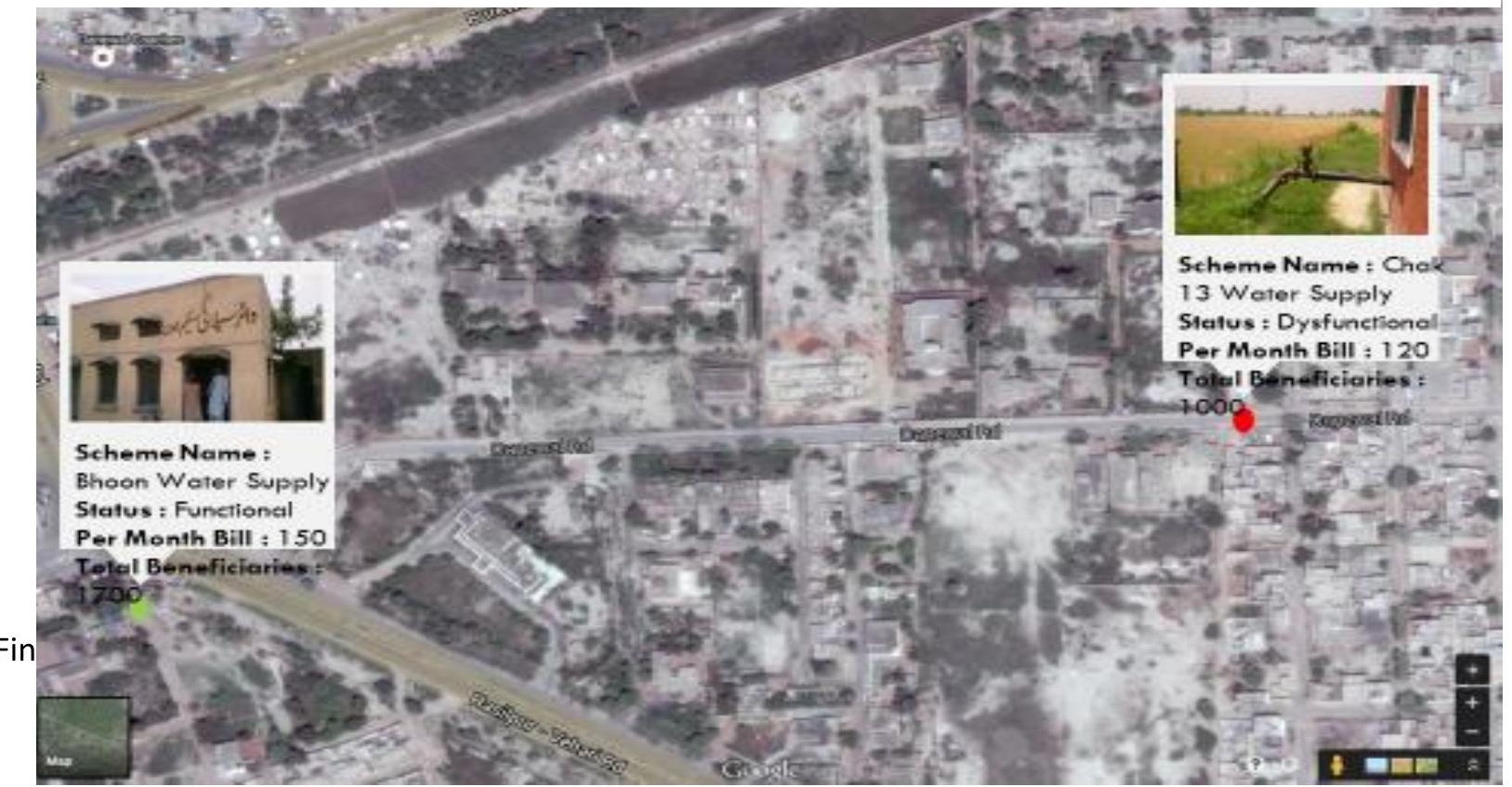


51. The system also features the capacity to send mobile phone alerts to relevant PHED staff. If a scheme is shown red for last 2 months the system will send a mobile phone alert to relevant CDU staff to check the cause in the field and report back in the system. The CDU staff report on the cause of failure in the system and this forms the basis for the district head of PHED to assign actions to relevant staff. Once the action is taken by staff it is again reflected in the system. If any staff fails to take action on task assigned, a remainder is sent and finally after passing a threshold number of days a non-compliance report is sent to management.

52. Access to the dashboard is available to the concerned district and head office staff of PHED. PHED management also has access to dash board and can view how many schemes were functional in each district in any given month, the actions taken by field staff on red schemes and compliance.

53. In addition to sending normal the monthly question on the status of schemes, the system has started sending one additional questions to consumers. These questions have been framed to obtain information on the number of hours of water supply per day, the average monthly water bill and the levels of satisfaction with the performance of the CBO.

54. Another important aspect of this component of the TA was obtaining information on the poverty dimensions of the CBO management of schemes. The three poor districts of R.Y Khan, Bahawalpur and Kasur were compared against the relatively well-off districts Chakwal, Gujrat and Vehari.

Figure 11: Tariffs, Numbers of schemes and Poverty Concentration in Six Districts

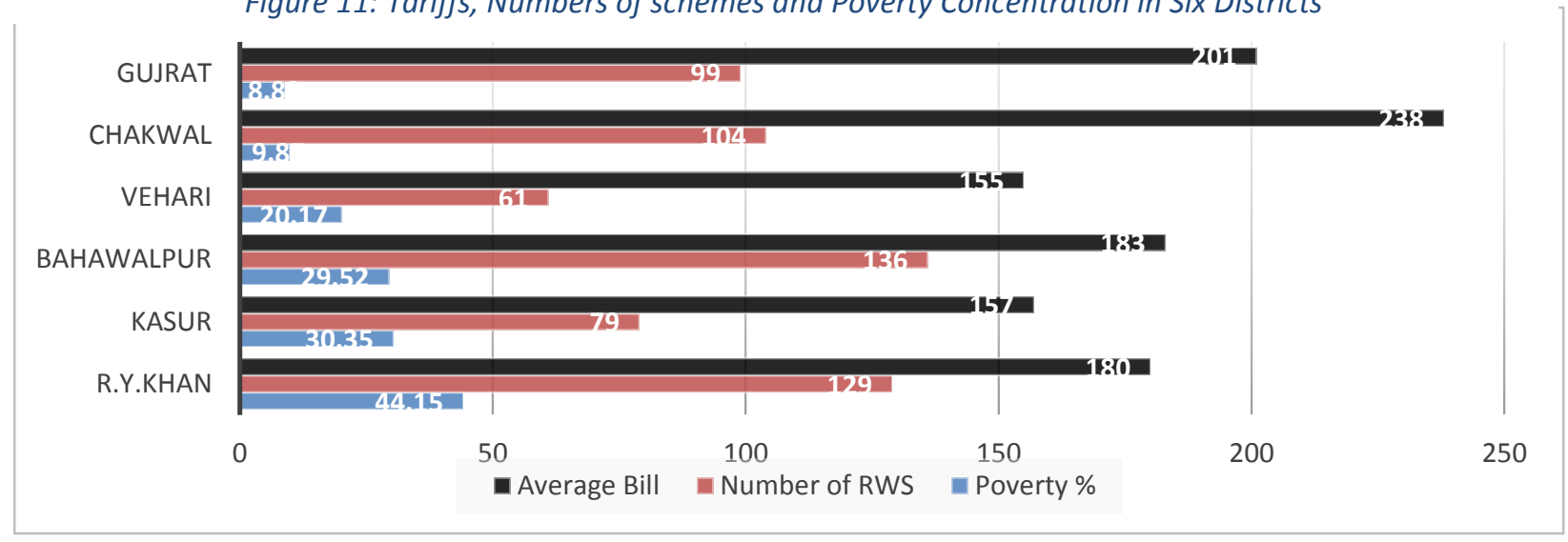

Final Output - Strengthening Local Providers for Improved Rural Water Supply in Pakistan (P131990) 
55. The data of Benazir Income Support Program (BISP) ${ }^{7}$ was used for the poverty ranking of these districts. Information on the tariffs, hours of supply, persons per schemes, concentration of the poor in each district was collected from the six districts. This data was used to calculate the status of service delivery, the concentration of infrastructure, the unit cost of production and revenue collection efficiency in both sets of districts.

${ }^{7}$ The BISP is Government of Pakistan Social Safety Net Program. BISP has identified poor households through a country-wide Poverty census and collected information on the various characteristics of the household as well as its assets. 
Table 4: District RWS Poverty Comparisons

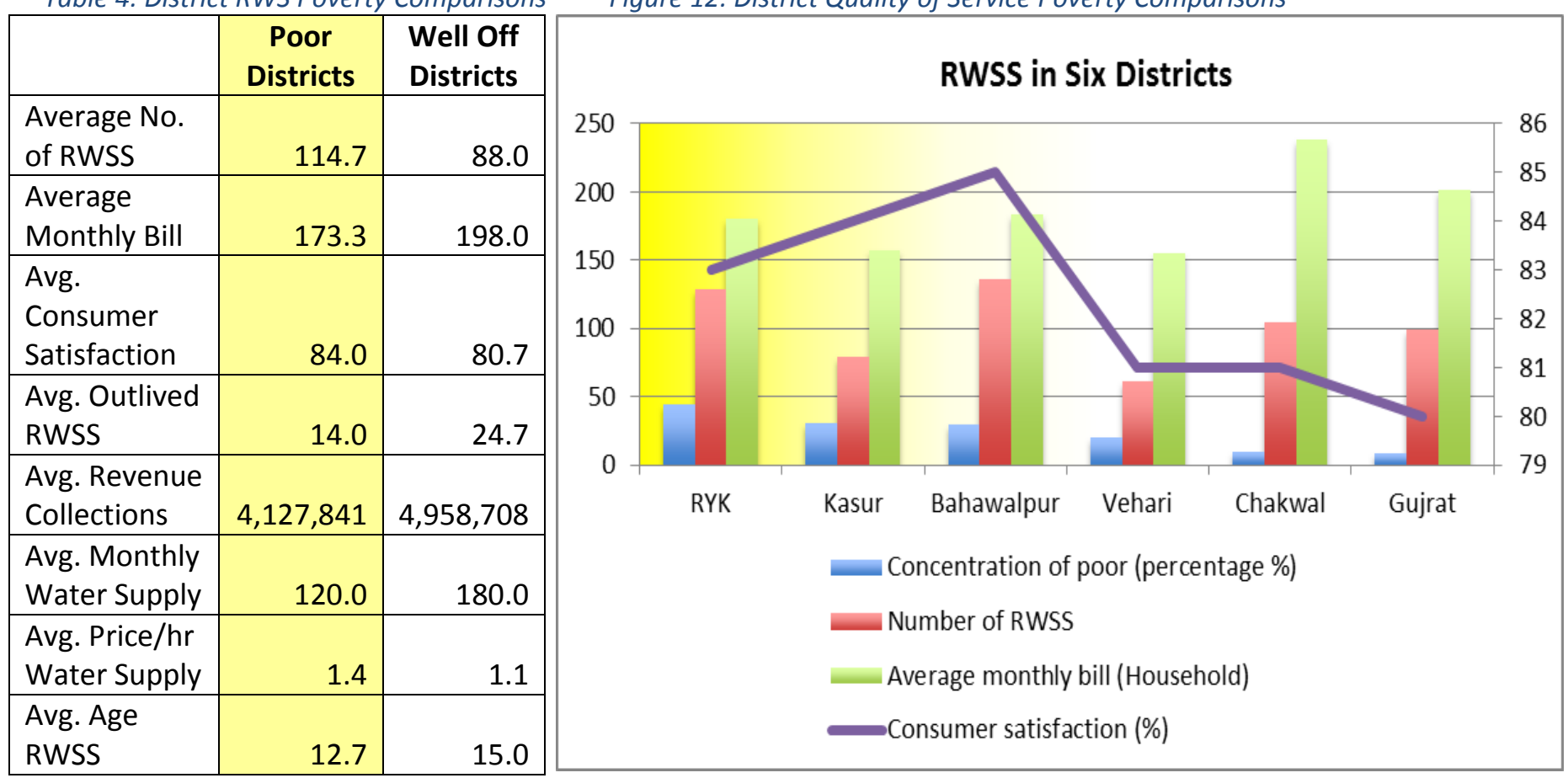

56. Major challenges were building the acceptability and ownership of this initiative within PHED particularly at the district level. Then the building of the capacity of PHED staff in geo-tagging, obtaining cell numbers of beneficiaries and authenticity of data was a big challenge. It took considerably more time than planned to get quality and credible data from the field. Inculcating a culture of relying to SMS and IVR calls by consumers was extremely difficult. Special awareness sessions were designed to build the confidence and habit of responding to SMS and IVR calls. This may also remain a challenge in future and require constant engagement with community.

57. PHED has allocated Rs. 16 M (US\$ 160,000) in FY 2016 to bear the cost of SMS and IVR calls to beneficiaries. The integration of this system has been completed with PHED MIS. The PHED through GoPunjab has approached the WB to scale up this pilot in remaining 30 districts of Punjab under on "Punjab Public Management Reform Program - PRMP". UNICEF has also showed keen interest in the approach, methodology of this system and was impressed with results. UNICEF is in advance stage of negotiating with PHED on replication of this system for rural sanitation sector in Punjab. The biggest challenge which still lies ahead is the use of this tool by the middle management of PHED. 


\section{CBOs Performance Award Competition}

Outputs:

\section{Annex G - $2^{\text {nd }}$ CBO Performance Award Competition (PAC)}

58. This TA component supported PHED in conceiving, designing and organizing the CBO Performance Award Competitions. The CBO Performance Award Competition (PAC) was an initiative which sought to:

- Infuse a spirt of competition among CBOs for improving services

- Provide a platform for networking, learning and show casing best practices

- Formally recognize services of CBOs

The annexed report summarizes the approach, the process and the proceedings of the $2^{\text {nd }} C B O s$ PAC that was conducted in 2013.

59. Through this TA the idea of the PAC was introduced, the concept note developed and financial support extended to organize the $1^{\text {st }}$ and $2^{\text {nd }}$ PAC with over $300 \mathrm{CBO}$ s and PHED staff represented in each event. This TA introduced the concept of $\mathrm{CBO}$ s evaluation by independent panelists, devised the evaluation criterion of $\mathrm{CBO}$ s performance (based on IB Net indicators performance indicators) and provided logistical support to PHED. This TA not only tried to institutionalize this initiative within PHED but also expand development partner support for the PAC in collaboration with UNCEF.

60. The CBO Performance Award Competitions consists of four stages:

- Self-nomination of CBOs for PAC through Expression of Interest (EOI) form;

- Short listing of EOIs by PHED district staff;

- Field verification of shortlisted CBOs trough a $3^{\text {rd }}$ party;

- Evaluation of shortlisted CBOs by a panel of judges.

61. Each step in the selection process comprised of a well-established judgement criteria for filtering out $\mathrm{CBO}$ s on the basis of their performance. In the $2^{\text {nd }} \mathrm{CBOs}$ PAC nearly $1,500 \mathrm{EO}$ forms were collected by CBOs, a total of 750 EOls were submitted, 250 CBOs were shortlisted by district based PHED staff, 179 CBOs were subject to $3^{\text {rd }}$ party validation of their performance and 67 CBOs were invited for a final round of evaluation by a panel judges in a three days gathering of CBOs.

62. The $\mathrm{CBOs}$ were awarded in the category of Best District $\mathrm{CBO}$, divisional $\mathrm{CBO}$ and best provincial $\mathrm{CBO}$. Other special awards were presented in categories such as 100 percent cost recovery, maximum savings, gender participation, innovation and record keeping. Some highlights of CBOs performance showcased in the last two CBO PACs include:

- $\quad$ CBOs realigning their rising main and distribution networks to minimize water losses including the extension of the distribution network and installation of new pumping (backup) machinery;

- $\quad \mathrm{CBOs}$ utilizing their savings or leveraging other sources of funds to make major investments in the expansion and rehabilitation of schemes;

- $\mathrm{CBOs}$ investing in back-up power supplies in the form of heavy duty diesel generators in the wake of frequent power cuts;

- $\quad$ CBOs using computerized billing systems, running wireless and mobile phone based complaint redressal systems, maintaining bank accounts and carrying out annual audits of their accounts through professional chartered accounting firms;

- CBOs covering $100 \%$ of their operating costs (energy bills, salaries and maintenance) from consumers through flat or volumetric (metering households) tariffs. 
- $\mathrm{CBOs}$ covering the costs of installing meters from operational revenues to improve demand management, equity of service delivery and fair tariff setting.

- With CBO tariffs ranging from Rs. $70-500 /$ month (US\$ $070-5$ ), many CBOs have significant savings with some CBOs having saved Rs. 32 M (US\$ 320,000).

- $\quad \mathrm{CBO}$ are keeping good records and allowing open access to this information with women playing a vital role in some CBOs in maintaining these records.

- $\quad \mathrm{CBOs}$ graduating and registering as NGOs to work in other social service sectors after gaining experience in the rural water sector.

63. The objective of this TA, apart from supporting PHED to host these events, was to institutionalize this process within the PHED system. As the major partner of PHED in conceiving and implementing the $1^{\text {st }}$ CBOs PAC, this TA partnered with UNICEF in organizing the $2^{\text {nd }} C B O s$ PAC. UNICEF is the lead partner for the $3^{\text {rd }}$ CBOs PAC which is an indication of how this TA has fostered partnerships and influenced resources. The $3^{\text {rd }} \mathrm{CBO} P A C$ is currently in the $3^{\text {rd }}$ stage (i.e. the $3^{\text {rd }}$ party field verification of 260 shortlisted CBOs is currently underway). The fourth and final stage (i.e. the evaluation of shortlisted CBOs by a panel of judges) will be organized in May 2016 by UNICEF.

64. Integrating the CBOs PAC within PHED's ADP remains a challenge. Although the senior management of the PHED is convinced of the benefits of the PAC the authorizing departments like Finance and Planning prefer to allocate government resources for hardware (construction of new schemes). By inviting representatives of the Planning and Finance Departments to the final stage of $3^{\text {rd }}$ CBO PAC it is sought to convince them of the effectiveness of this platform so that they might approve the allocation of funds for PHED to finance the $4^{\text {th }}$ CBOs PAC in 2017.

\section{Capacity Building of Stakeholders}

Outputs:

Annex F - Training Report of PHED and CBOs

65. This TA component supported the capacity building of CBOs and PHED staff to deliver and sustain quality rural water supply services. This component was designed and executed to bridge the gap between PHED (technical and CDU staff) and CBOs. The annexed training report summarizes the content and results of the training of $\mathrm{CBO}$ and PHED staff.

66. Initial discussions were held with PHED senior management on the content of the training and the training modalities, the criteria for the selection of participants, the duration of the training and other logistics. The training was focused on social mobilization, $M \& E$, communications, gender mainstreaming, financial management, customer services, technical aspects of scheme management, water quality, social accountability and hygiene.

- A total of eight training sessions were organized at the divisional headquarters. The participants of the training sessions were one third PHED staff and two thirds CBO members. Women staff of PHED participated as trainers and trainees to promote a greater role for women within CBOs.

- In each training session most of the content was delivered by PHED staff and CBO champions. These champions were identified through a process designed not only to identify capacities in particular areas (i.e. preventive maintenance; record keeping; meter reading; water quality) but also to build confidence and inspire the participants.

- All training manuals designed through this TA were approved by PHED. The materials developed through this TA to collate performance indicators, reporting templates and record keeping registers were also printed and shared with CBOs.

Final Output - Strengthening Local Providers for Improved Rural Water Supply in Pakistan (P131990) 


\section{Establishment of the Sector Reform Unit (SRU)}

Outputs:

$\{$ Annex G - Concept Paper on Sector Reform Unit (SRU)

67. The establishment of the Sector Reform Unit (SRU) in Khyber Pakhtunkhwa (KP) was an additional initiative supported through this TA. Following a series of meetings and field visits in Punjab by PHED staff from KP, the GoKP requested the support of this TA to establish the SRU within the PHED,

68. This TA supported the conception, design and establishment of the PHED SRU in KP as a think tank fire walled from the project based implementation of infrastructure. The SRU mandate is to undertake research, monitoring \& evaluation, capacity building and supporting field units in the delivery of rural water services. The SRU is structured to be a demand responsive unit responding to the needs of field offices. In addition, the SRU will act as the focal point for donor coordination in the drinking water sector.

69. While this TA took the lead in designing the concept and the structure of the SRU, other partners like UNICEF and SDC are supporting PHED to strengthen the SRU by investing in the human resource and program needs of SRU. The allocation of RS $60 \mathrm{M}$ (US\$ 6.0 M) in the FY 2015-16 budget and the amendment of the PHED organogram to reflect SRU are the indicators of commitment of the Government of KP to this initiative.

70. A senior staff member has been assigned as Chief SRU and given staff by the department. A SRU has developed its two years program with support of partners and is procuring services of specialist to undertake the program activities. The annexed concept paper captures the rationale, structure, scope and mandate of SRU. 